\title{
Functional Diversification of Cerato-Platanins in Moniliophthora perniciosa as Seen by Differential Expression and Protein Function Specialization
}

\author{
Mario R. de O. Barsottini, ${ }^{1,2}$ Juliana F. de Oliveira, ${ }^{2}$ Douglas Adamoski, ${ }^{2}$ Paulo J. P. L. Teixeira, ${ }^{1}$ \\ Paula F. V. do Prado, ${ }^{1,2}$ Henrique O. Tiezzi, ${ }^{2}$ Mauricio L. Sforça, ${ }^{2}$ Alexandre Cassago, ${ }^{3}$ \\ Rodrigo V. Portugal, ${ }^{3}$ Paulo S. L. de Oliveira, ${ }^{2}$ Ana C. de M. Zeri, ${ }^{2}$ Sandra M. G. Dias, ${ }^{2}$ \\ Gonçalo A. G. Pereira, ${ }^{1,2}$ and Andre L. B. Ambrosio ${ }^{2}$ \\ ${ }^{1}$ Departamento de Genética e Evolução, UNICAMP, Campinas, SP 13083-970, Brazil; ${ }^{2}$ Laboratório Nacional de Biociências, \\ CNPEM, Campinas, SP 13083-100, Brazil; 'Laboratório Nacional de Nanotecnologia, CNPEM, Campinas, SP 13083-100, \\ Brazil
}

Submitted 8 March 2013. Accepted 22 July 2013.

Cerato-platanins (CP) are small, cysteine-rich fungalsecreted proteins involved in the various stages of the host-fungus interaction process, acting as phytotoxins, elicitors, and allergens. We identified $12 \mathrm{CP}$ genes (MpCP1 to $\mathrm{MpCP12)}$ in the genome of Moniliophthora perniciosa, the causal agent of witches' broom disease in cacao, and showed that they present distinct expression profiles throughout fungal development and infection. We determined the X-ray crystal structures of MpCP1, MpCP2, MpCP3, and MpCP5, representative of different branches of a phylogenetic tree and expressed at different stages of the disease. Structure-based biochemistry, in combination with nuclear magnetic resonance and mass spectrometry, allowed us to define specialized capabilities regarding selfassembling and the direct binding to chitin and $\mathrm{N}$-acetyl-

Nucleotide sequences were deposited at the GenBank under the accession numbers JX847578 (MpCP6), JX422024 (MpCP7), EU250343 (MpCP8), JX422025 (MpCP9), JX847579 (MpCP10), JX422026 (MpCP11), JX422027 (MpCP12), JX422037 (SMpCP1), JX422028 (SMpCP2), JX422029 (SMpCP3)，JX422036 (SMpCP6)，JX422030 (SMpCP7), JX422031 (SMpCP8), JX422032 (SMpCP9), JX422033 (SMpCP10), JX422034 (SMpCP11), JX422035 (SMpCP12), JX422041 (CcCP1), JX422043 (CcCP2), JX422039 (CcCP3), JX422042 (CcCP4), JX422040 (CcCP5), JX422044 (CcCP6), JX422038 (MrCP1), JX426104 (MrCP2), JX426107 (MrCP3), JX426108 (MrCP5), JX426106 (MrCP6), JX426113 (MrCP7), JX426110 (MrCP8), JX426105 (MrCP9), JX426109 (MrCP10), JX426112 (MrCP11), and JX426111 (MrCP12).

The atomic coordinates and structure factors under PDB ID 3SUJ (MpCP1), 3SUK (MpCP2), 3SUL (MpCP3), and 3SUM (MpCP5) are available at the Protein Data Bank.

M. R. de O. Barsottini, J. F. de Oliveira, and D. Adamoski contributed equally to this work. S. M. G. Dias and A. L. B. Ambrosio contributed equally to this work.

Corresponding authors: A. L. B. Ambrosio or S. M. G. Dias; E-mail: andre.ambrosio@lnbio.cnpem.br or sandra.dias@lnbio.cnpem.br; Telephone: +(55) 193512 1115; Fax: +(55) 1935121004.

* The $\boldsymbol{e}$-Xtra logo stands for "electronic extra" and indicates that nine supplementary figures, three supplementary tables, and supplementary information about experimental procedures are published online.

(C) 2013 The American Phytopathological Society glucosamine (NAG) tetramers, a fungal cell wall building block, and to map a previously unknown binding region in MpCP5. Moreover, fibers of MpCP2 were shown to act as expansin and facilitate basidiospore germination whereas soluble MpCP5 blocked NAG6-induced defense response. The correlation between these roles, the fungus life cycle, and its tug-of-war interaction with cacao plants is discussed.

The basidiomycete Moniliophthora perniciosa is the causal agent of the witches' broom disease (WBD) and considered one of the major fungal plagues of cacao crops (Aime and Phillips-Mora 2005). WBD severely affects the production of cocoa beans, the raw material of chocolate and other derivatives, resulting in great agro-economic losses throughout the cultivating fields of Central and South America (Evans 2007). In this regard, it is urgent to gain knowledge on important proteins for the fungus attack onto the plant.

Defense responses in plants upon a pathogen attack usually result in deposition of callose and production of reactive oxygen species, nitric oxide, and phytoalexins, along with the transcription of defense-related genes (Desender et al. 2007). These responses are promoted by elicitors, which are recognized by plant receptors. They initiate the microbe-associated molecular pattern (MAMP)-triggered immunity or induce a second layer of defense called the effector-triggered immunity (Jones and Dangl 2006).

One family of elicitors spread among the fungal kingdom is the cerato-platanin (CP) family. The founding member of this family and the most studied protein is $\mathrm{CP}$ from Ceratocystis platani (CpCP) (Pazzagli et al. 1999). CpCP, recently characterized as a MAMP, induces defense responses and tissue necrosis in plants (Fontana et al. 2008; Lombardi et al. 2013; Pazzagli et al. 1999) and may have a structural role in fungal cell wall formation (Baccelli et al. 2012; Boddi et al. 2004). The tridimensional structure of $\mathrm{CpCP}$ was determined by nuclear magnetic resonance (NMR) and is similar to proteins that bind to polyssacharides (de Oliveira et al. 2011). The CpCP interacts with chitin (an unsoluble polymer of $\mathrm{N}$-acetylglucosamine [NAG]) and soluble NAG oligomers (Baccelli et al. 2013, de Oliveira et al. 2011) and, although it does not bind to cellulose, 
CpCP loosens it, which could be important during host colonization (Baccelli et al. 2013). Pop1, a CpCP homologue found in C. populicola, shares many of these features. Indeed, it was demonstrated that both $\mathrm{CpCP}$ and Pop1 form soluble ordered aggregates under mild denaturing conditions, which are believed to be important for fungal development and virulence (Baccelli et al. 2013; Carresi et al. 2006; Comparini et al. 2009; Lombardi et al. 2013; Martellini et al. 2012; Pazzagli et al. 2009). Other $\mathrm{CP}$ present diverse biological activities, such as the induction of systemic acquired resistance (SAR) and induced systemic resistance (ISR) in plants, linked or not to tissue necrosis (Djonović et al. 2007; Frías et al. 2011, 2013; Hall et al. 1999; Vargas et al. 2008; Wilson et al. 2002). Epl1 from the beneficial, root-colonizing fungus Trichoderma atroviride was shown to be able to aggregate in a quick and ordered fashion, although no biological role of such aggregates was presented (Frischmann et al. 2013). The antigen CS-Ag from Coccidioides immitis, a human pathogen, has proteolytic activity (Pan and Cole 1995). All these functions attributed to the $\mathrm{CP}$ proteins make them an attractive target to control the pathogen attack.

The recent completion of $M$. perniciosa's genome sequencing allowed us to identify an astonishingly high number of $\mathrm{CP}$ coding genes; more precisely, 12 in total (MpCP1 to MpCP12). In this article, we show that they are clearly differentially expressed throughout the several stages of the disease, as well as the different stages of fungus development. Accordingly, the co-expressed proteins clustered into distinct branches of an allencompassing phylogenetic tree, indicating the presence of groups with higher sequence similarity and, likely, functional proximity. In order to test this hypothesis, we heterologously expressed, purified, and determined the crystallographic structure of four representative members of the distinct phylogenetic clusters: MpCP1, which is exclusively expressed in basidiocarps; $\mathrm{MpCP} 2$ and $\mathrm{MpCP} 3$, both detected in the fast growing mycelium and necrotic-infected seed and fruit; and MpCP5, majorly detected during the slow growth in the apoplast, where plant attack is set. Curiously, MpCP5 structure was found to be essentially different from any other determined to date. The $\mathrm{X}$-ray crystal structures guided the subsequent investigation of the capacity of $\mathrm{MpCP}$ to bind to fungus and plant cell wall components, as well as to self-aggregate into amyloid-like filaments. In this sense, NMR analysis showed that MpCP3 and MpCP5 distinctly bind to NAG tetramers (NAG4) with different affinities and allowed the description of an unforeseen binding interface in MpCP5. The MpCP5 presence was sufficient to block NAG6-induced defense response in tobacco seedlings, representing the first $\mathrm{CP}$ shown to counteract the chitin fragment plant sensitization. Finally, we show that $\mathrm{MpCP} 2$ and MpCP3 are the most responsive to self-aggregation into amyloid-like fibrils, with the fibrils of the former acting as expasins and also promoting germination tube growth. The described biological activities of MpCP5 and MpCP2 are in accordance with their expression profile during the host-fungus interaction and exemplify the protein function specialization of MpCP during the WBD of cacao.

\section{RESULTS}

\section{M. perniciosa possesses}

multiple differentially expressed $\mathrm{CP}$ genes.

M. perniciosa has a hemibiotrophic life cycle starting with meristem- and young fruit-infecting basidiospores that induce hyperplasia and irregular branching of actively growing tissues of the cacao tree. During this stage, called the biotrophic phase, hyphae are formed in the host's intercellular space. The disease then progresses to a necrotic stage, during which the fungus grows intracellularly, resulting in the death of the plant tissues (giving rise to the dry-broom aspect of the branches) and the development of fruiting bodies (necrotrophic phase) (Meinhardt et al. 2008).

In addition to the five $\mathrm{CP}$ originally described by Zaparoli and colleagues (2009) in the fungus M. perniciosa (MpCP1 to MpCP5; National Center for Biotechnology Information GenBank accession codes EU250339, EU250340, EU250342, EU250344, and EU250345, respectively), we present here seven new genes. It is yet worth mentioning that the CERAT gene, previously identified by Rincones and colleagues (2008), corresponds to MpCP3. An Aspf13 homologue was also described, and verified by us to match the MpCP2 gene (Leal et al. 2010). Given the new apparent redundant number of isoforms (MpCP1 to $\mathrm{MpCP} 12$ ), we first set out to analyze their individual mRNA expression patterns throughout the different stages of the disease. RNA-seq data from greenhouse-grown cacao plants infected with $M$. perniciosa revealed that $\mathrm{MpCP} 4,5,11$, and 12 are prominently expressed in the green parts-infecting fungus (biotrophic phase). Their gene expression levels decrease as the disease progresses, until complete disappearance when the dry broom stage is reached (Fig. 1A). Second, MpCP2 and MpCP3 are virtually the only two isoforms present in $M$. perniciosa from field-collected, infected fruit (Fig. 1B) and in the mycelium of in vitro lab-cultivated fungus (Fig. 1C). MpCP1 is basically the only isoform detected during basidiocarp formation, while MpCP4 and MpCP11 dominated the basidiospore phase. MpCP 6, 7, 8, 9, and 10 presented no significant
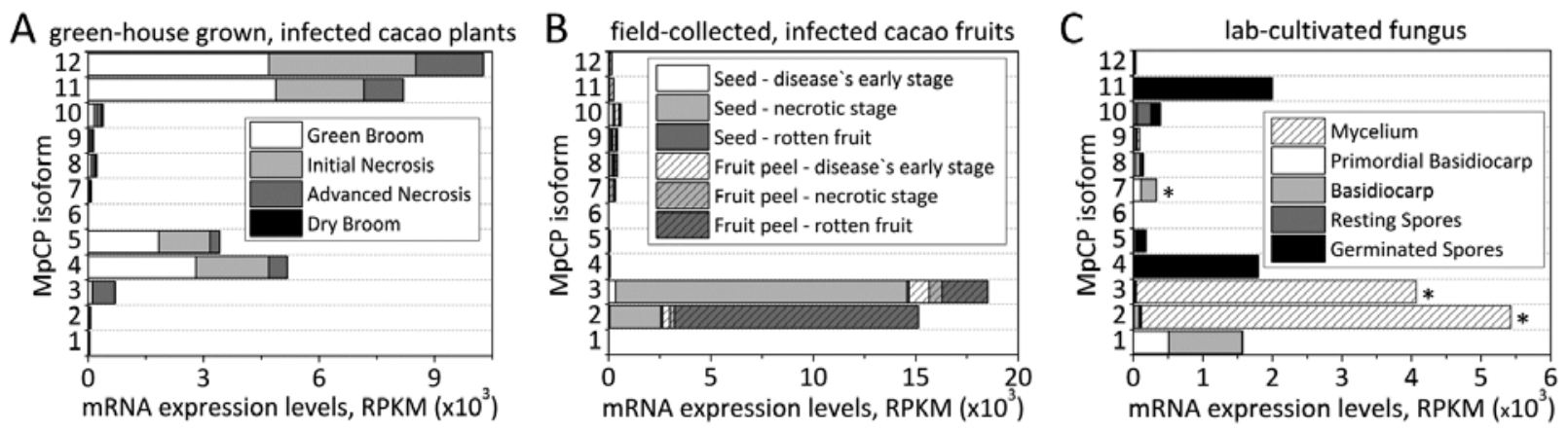

Fig. 1. Differential expression of MpCP1 to MpCP12 throughout the stages of fungal development and infection. A, Of 12 cerato-platanin (CP)-coding genes identified in Moniliophthora perniciosa, only transcripts from isoforms 4, 5, 11, and 12 were detected in the biotrophic fungus. A decrease in their expression levels was observed as the disease progressed, until complete depletion when the dry-broom stage was reached. B, Inversely proportional levels MpCP2 and MpCP3 coding transcripts were measured when rotten, field-collected seed and fruit pods were analyzed. C, In samples extracted from labcultivated fungus, MpCP2 and MpCP3 transcripts were detected in the mycelium, whereas isoforms 4 and 11 were detected exclusively in germinated basidiospores. MpCP1 was detected only in basidiocarps. Asterisks indicate isoforms that were detected at protein level, by mass spectrometry, in the culture medium of in-vitro-grown necrotrophic mycelium. RPKM = reads per kilobase of exon model per million mapped reads. 
gene expression throughout all the samples and stages analyzed. Mass spectrometry analysis of $M$. perniciosa's culture medium of in-vitro-grown necrotrophic mycelium was further performed to allow the direct identification of the proteins. Accordingly, MpCP 2, 3, and 7 proteins (Supplementary Table S1A) were identified, indicating that all other $\mathrm{MpCP}$ are likely only necessary during the fungus-cacao interaction. Glycosylation prediction using the NetNGlyc 1.0 online server revealed that MpCP 1, 2, 4, 5, and 11 contain one putative glycosylation site $(\mathrm{NxS} / \mathrm{T})$, which is equivalent to the one described for the protein Sm1 as important to modulate protein dimerization and plant recognition (29NGS31) (Vargas et al. 2008). Additional putative glycosylation sites were also identified for these MpCP. Two of the three spectrometry-identified MpCP2 peptides spanned the SM1-homologue glycosylation site, indicating that, if this protein is glycosylated on this segment, it is only partially.

Phylogenetic analysis of $M$. perniciosa's CP proteins.

The clear differential expression profiles of MpCP transcripts led us to speculate whether these isoforms might have distinct roles during the fungus development or plant infection process. In order to evaluate the evolutionary relationships between the homologous sequences and gain insights into their specific roles, we reconstructed the CP phylogenetic tree using deposited homologous sequences (Fig. 2). The group of sequences included recently deposited genes from another cacao-infecting fungus, $M$. roreri $(\mathrm{MrCP} 1$ to $\mathrm{MrCP} 10)$, as well as the $M$. perniciosa biotype $\mathrm{S}$, which infects plants of the

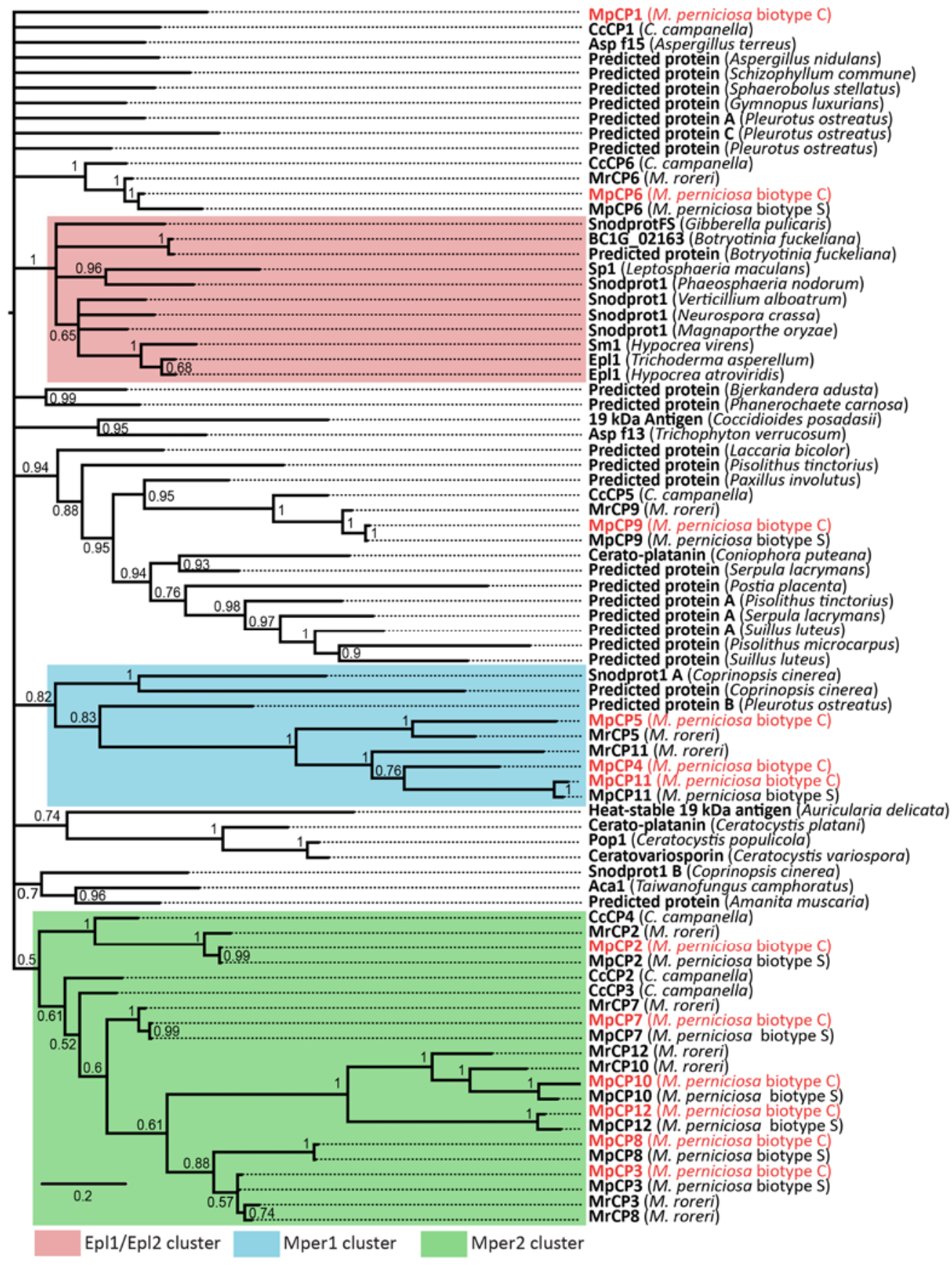

Fig. 2. Phylogenetic reconstruction of the cerato-platanin (CP) family. Comprehensive evolutionary tree determined using deposited CP sequences. Four main clusters can be distinguished. Epl1/Epl2 (red box), in accordance with previously published analysis (Seidl et al 2006); Mper1 and Mper2, delimited by blue and green boxes, respectively; and the sequences from other basidiomycetes, together with MpCP9 (not highlighted). Numbers near branches are Bayesian posterior probabilities. 
Solanaceae family (Marelli et al. 2009) (SMpCP1 to SMpCP3 and SMpCP6 to SMpCP12), and the saprotrophic Crinipellis campanella ( $\mathrm{CcCP} 1$ to $\mathrm{CcCP} 6)$, representing a saprotrophic nonpathogenic ancestral of the Moniliophthora genus (Aime and Phillips-Mora 2005). The sequences clustered in three major groups. One group contains CP homologues from ascomycetes and is in accordance with previously published data (Seidl et al. 2006) regarding the clustering of the genes Sm1 (T. virens), Epl1 (Hypocrea atroviridis), SP1 (Leptosphaeria maculans), and Snodprot1 (Phaeosphaeria nodorum), among others, within the so-called Epl1/Epl2 cluster (Fig. 2, branches within light-red box). MpCP4, MpCP5, and MpCP11, as well as homologues from the basiodiomycetes Pleurotus ostreatus and Coprinopsis cinerea, determined the MpCP cluster 1 (Mper1) (Fig. 2, blue box). On the other hand, MpCP 2, 3, 7, 8,10 , and 12 grouped within the MpCP Cluster 2 (Mper2) (Fig. 2, green box) along with saprotrophic Crinipellis campanella's CP.

Mper clusters 1 and 2 are relatively distant in the evolutionary tree and, in accordance, comprise $\mathrm{MpCP}$ proteins that are co-expressed during different stages of the fungus development. Specifically, MpCP4, MpCP5, and MpCP11 (Mper1) are coexpressed during the fungus-cacao interaction (in the green or living parts of the plant) as well as during basidiospore germination, whereas MpCP2 and MpCP3 (Mper2) are highly expressed only in the necrotic infected fruit and in-vitro-grown mycelium. Finally, MpCP9, not significantly expressed in any of the cases analyzed, clustered with several putative $\mathrm{CP}$ homologues from basidomycetes. MpCP1 and MpCP6 did not significantly cluster into the cited groups.

This separation may suggest that MpCP4, MpCP5 and $\mathrm{MpCP} 11$ are important for the fungus-plant interaction process
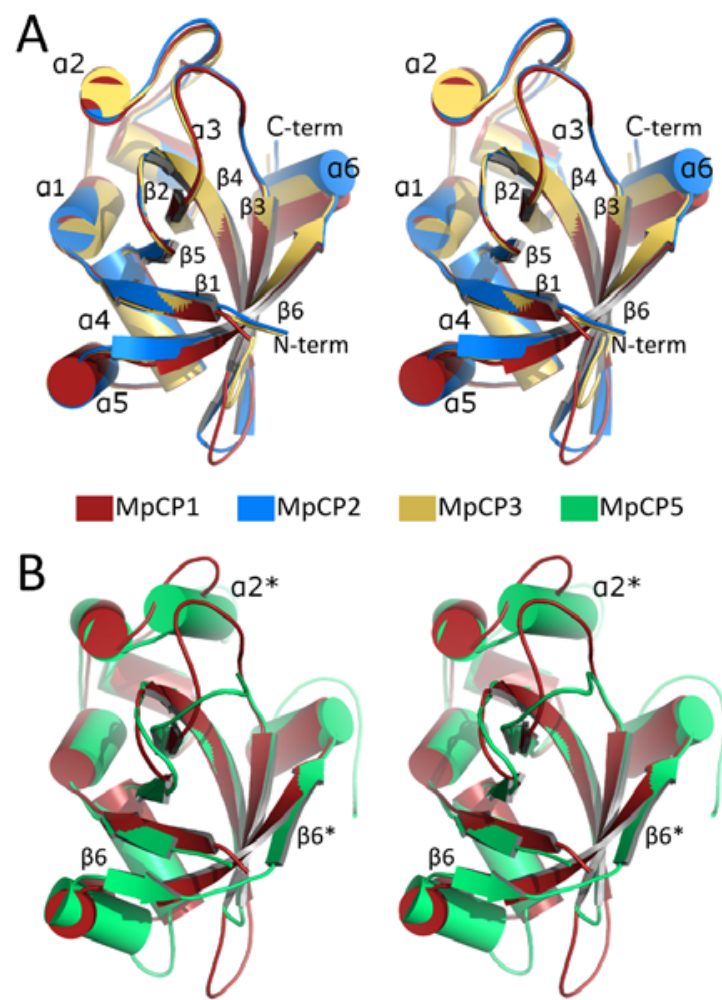

Fig. 3. Crystal structures of MpCP 1, 2, 3, and 5. Stereographic views in cartoon representations of superposed $\mathbf{A}, \mathrm{MpCP} 1-3$ and $\mathbf{B}, \mathrm{MpCP} 1$ and MpCP5. All four structures present the canonical double $\Psi \beta$-barrel, interspersed with helices. The major structural differences between MpCP5 and $\mathrm{MpCP} 1, \mathrm{MpCP} 2$, and $\mathrm{MpCP} 3$ are the length of the loop between sheets $\beta 2$ and $\beta 3$ and the hairpin connecting sheets $\beta 3$ and $\beta 4$. and that $\mathrm{MpCP} 2$ and $\mathrm{MpCP} 3$, as well as $\mathrm{MpCP} 1$, expressed in the basidiocarp, may have important developmental roles for the growth in a nutrient-rich environment. The combination of the above-mentioned data led us to conclude that the CP found in the M. perniciosa genome may have different roles important for distinct aspects of the WBD.

\section{X-ray structures.}

To unravel the different functions of the MpCP, we solved the crystal structure of selected recombinant MpCP expressed during the infection of green parts (MpCP5) and fruit (MpCP2 and $\mathrm{MpCP} 3$ ), as well as MpCP1, the major isoform during basidiocarp formation. Different constructs of a recombinant MpCP4 were also tested for solubility after Escherichia coli expression but all failed in producing soluble protein. The parameters and statistics for both data collection and processing and the final refined models are presented in Supplementary Table S2.

First, MpCP1 structure was solved by single-wavelength anomalous dispersion using the signal from seven intrinsic sulfur atoms (five cysteine and two methionine residues). The obtained model was then employed as search model for solving $\mathrm{MpCP} 2$ and $\mathrm{MpCP} 3$ structures by molecular replacement. MpCP5 could only be solved by molecular replacement using the elicitor Sm1 from T. virens (PDB ID: $3 \mathrm{M} 3 \mathrm{G}$ ) as search model. Regardless, the core fold of all MpCP consists of a sixstranded antiparallel $\beta$-sheet flanked by six $\alpha$-helices and loops, forming a double $\Psi \beta$-barrel (Fig. 3A). Also, all four structures presented the two disulfide bridges expected for this family of proteins (Supplementary Fig. S1). The overall MpCP1, MpCP2, and MpCP3 structures are highly conserved, with an average backbone root mean square deviation (r.m.s.d.) of $0.86 \AA$ and an average sequence identity of $49.4 \%$, as calculated by Coot (Emsley et al. 2010) (Fig. 3A). The major conformational variability between these three structures reside in a $\beta$-hairpin loop between strands 3 and 4 , along with some small divergences among other loops. The MpCP5 sequence is only $25 \%$ identical, on average, to MpCP1, MpCP2, and $\mathrm{MpCP} 3$, and this is reflected in an overall higher core r.m.s.d. of approximately $1.33 \AA$. MpCP5 has an extra $\alpha$-helix (labeled as $\alpha 2 *)$, and the $\beta$-strand $\beta 6$ previously identified on the other MpCP breaks down into two shorter $\beta$-strands (termed $\beta 6$ and $\left.\beta 6^{*}\right)$. Moreover, MpCP5 presents a shorter $\beta$-hairpin between strands 3 and 4 along with some other major conformational variability among the loops (Fig. 3B). Five strong peaks (over $7 \sigma$ in height) were observed in the Fourier difference electron density map for MpCP1 which, with respect to their contributions to the dispersive component of the scattering factor, were interpreted as zinc, sodium, and chloride ions (Supplementary Fig. S2). All of these ionic species are found in high concentration in the crystallization solution, with the exception of the chloride, which was present in the protein purification solution. No other extraneous density was found in the electron density maps of MpCP2, MpCP3, and MpCP5.

All the structures were analyzed using the DALI server (Holm and Rosenström 2010) as a means of identifying similar folds and inferring their functions. Using a Z-score cutoff of 10 , the best structural matches for all $\mathrm{MpCP}$ were the elicitor Sm1 from $T$. virens (PDB ID: 3M3G) and CpCP from Ceratocystis platani (PDB ID: 2KQA). Overall, all MpCP superposed well to both $\mathrm{Sm} 1$ and $\mathrm{CpCP}$, with r.m.s. deviations ranging between 1 and $1.3 \AA$ for the $\mathrm{C} \alpha$, indicating very high structural conservation between them. Still, by the same cutoff criteria, the DALI search identified two expansins, the bacterial EXPB1 (Yennawar et al. 2006) (PDB ID: 2HCZ) and EXLX1 from corn plants (Kerff et al. 2008) (PDB ID: 3D30), as well as the pollen allergen Phlp1 from the grass Phleum pratense 
(unpublished data) (PDB ID: 1N10). CpCP was shown to interact with polymeric chitin oligomers of NAG, a sugar constituent of the fungus cell wall (Baccelli et al. 2013; de Oliveira el at. 2011). EXPB1 binds to maize cell walls, most strongly to xylans, causing loosening of the plant cell wall (Yennawar et al. 2006). EXLX1 binds to cellulose and peptidoglycan but it lacked catalytic activity against these substrates (Kerff et al. 2008). Therefore, the structural similarities clearly suggest that the MpCP may bind sugar molecules and that this interaction may be important for the plant-pathogen interaction.

\section{NMR titration shows that NAG4 binds}

\section{to distinct sites of MpCP3 and MpCP5.}

We next tested the ability of the MpCP 1, 2, 3, and 5 to bind NAG monomer and tetramer (NAG4), as well as determined the dissociation constants of these sugars, by NMR spectroscopy. NAG monomer at $10 \mathrm{mM}$ and a range of NAG4 concentrations from $100 \mu \mathrm{M}$ to $10 \mathrm{mM}$ were titrated against $50 \mu \mathrm{M}$ ${ }^{15} \mathrm{~N}$-labeled MpCP $1,2,3$, and 5 while monitoring the chemical shift and line width changes in the ${ }^{15} \mathrm{~N}$-HSQC spectra. Even a 200 times molar excess of NAG did not cause any perturbations to the ${ }^{15} \mathrm{~N}-\mathrm{HSQC}$ spectra of all tested MpCP (Supplementary Fig. S3A). However, when tested in the presence of NAG4, both ${ }^{15} \mathrm{~N}-\mathrm{MpCP} 3$ and ${ }^{15} \mathrm{~N}-\mathrm{MpCP} 5$ spectra were clearly perturbed. No significant changes were observed in the spectra of ${ }^{15} \mathrm{~N}-\mathrm{MpCP} 1$, whereas ${ }^{15} \mathrm{~N}-\mathrm{MpCP} 2$ was slightly disturbed in the presence of NAG4.

By triple-resonance experiments, we identified the NAG4binding surface and calculated the binding affinity to NAG4 for both MpCP3 and MpCP5. Peaks corresponding to residues Phe32, Thr34, Ala36, Cys37, Asp39, Trp68, and Asn69 in $\mathrm{MpCP} 3$ are those which have undergone the most perturbation upon NAG4 binding (Fig. 4A, left panel), based on a chemical shift cut-off criteria of $\Delta \delta\left({ }^{15} \mathrm{~N}+{ }^{1} \mathrm{H}\right) \geq 0.05 \mathrm{ppm}$. These residues are part of a region that is structurally similar to the one previously described for CpCP (de Oliveira et al. 2011) and lies mainly within the helix $\alpha 2$ and the loops between helices $\alpha 2$ and $\alpha 3$ and $\beta$-strands $\beta 2$ and $\beta 3$. The estimated dissociation constant $\left(\mathrm{K}_{\mathrm{d}}\right)$ for the MpCP3-NAG4 interaction, based on the chemical shifts of eight consecutive residues, according to previously published methodology (Lehotzky et al. 2010), was $24.7 \pm 12.8 \mathrm{mM}$ (Fig. 4B, upper panel). Strikingly, the MpCP5 peak assignment showed a rather extended, completely unforeseen, NAG4-interacting surface on this protein. The mapped region, as judged by chemically shifted and signal-faded (cutoff of -0.5 ) peak residues, is confined mainly at the C-terminus portion of MpCP5 (Fig. 4A, left panel). Accordingly, NAG4 binds to MpCP5 with a higher estimated affinity, as judged by a $K_{d}$ of $6.6 \pm 1.7 \mathrm{mM}$ (Fig. 4B, lower panel). These results show that MpCP3 binds NAG4 through a conserved surface
A

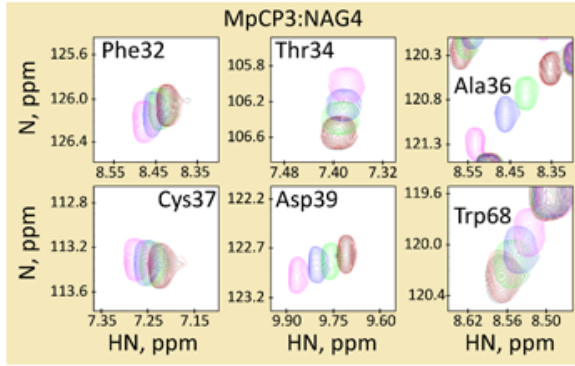

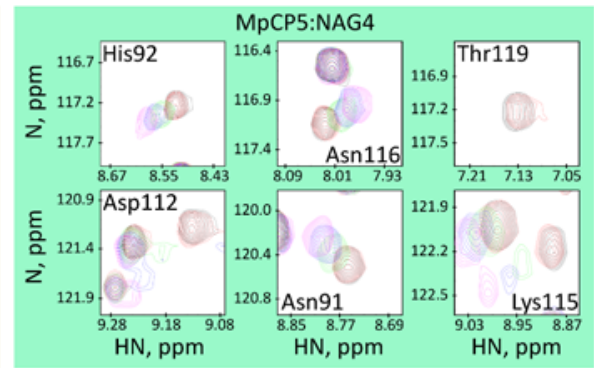

B MPCP5(50 $\mu \mathrm{M}):$ NAG4
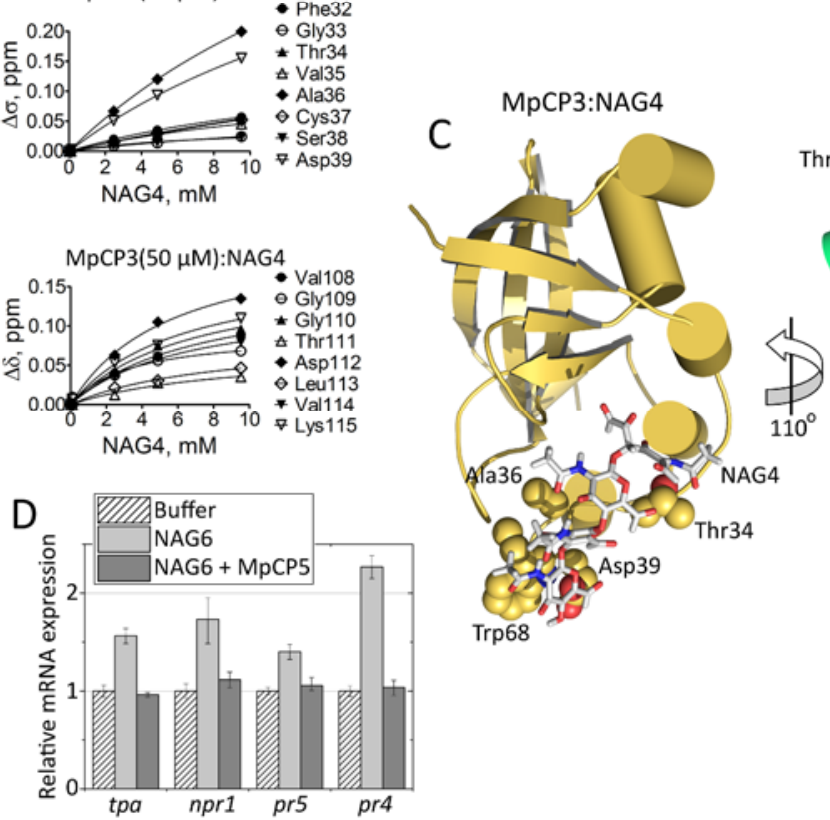

MPCP5:NAG4

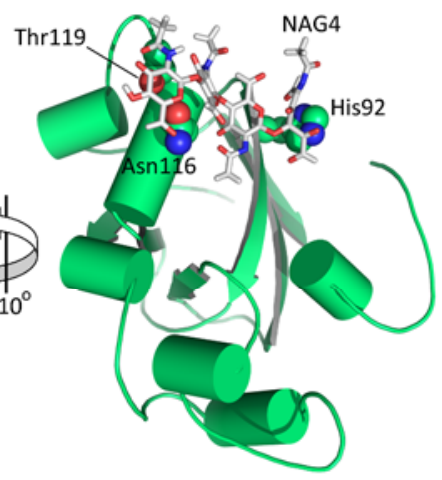

Fig. 4. MpCP3 and MpCP5 bind to $\mathrm{N}$-acetylglucosamine tetramer (NAG4), though at distinct regions. A, Overlay of regions of ${ }^{15} \mathrm{~N}-\mathrm{HSQC}$ spectra of ${ }^{15} \mathrm{~N}$-labeled MpCP3 (left panels) and MpCP5 (right panels), both proteins at $0.5 \mathrm{mM}$, without NAG4 (black), and titrated with $0.1 \mathrm{mM}$ (red), $2.5 \mathrm{mM}$ (green), $5 \mathrm{mM}$ (purple), and $10 \mathrm{mM}$ (pink) NAG4, highlighting some of the shifted and diminished residue peaks. All spectra were acquired with the same number of scans. B, Curve fitting of the NAG4 concentration plotted against the $\Delta \delta$ of specified residues used for the dissociation constant calculation. C, Computational blind docking models for the interactions between MpCP3 and MpCP5 with NAG4. NAG4 is represented by sticks and NAG4-interacting residues are represented as spheres. D, Relative mRNA expression levels of defense-related tobacco genes after treatment with NAG6 (400 nM) or MpCP5 (40 $\mu$ M) preincubated NAG6. 
regarding the $\mathrm{CpCP}$. MpCP5, on the other hand, binds to NAG4 through an unforeseen surface and with a higher affinity.

To get a picture of the putative binding mode of NAG4 to MpCP3 and MpCP5, we performed computational blind docking. The MpCP3-NAG4 lowest energy model obtained showed a binding surface that matched the residues disturbed by NAG4 interaction, as verified by the NMR experiments (Fig. 4A and C, left panels). On the other hand, the MpCP5NAG4 second lowest energy model indicated that NAG4 may bind to part of the otherwise large disturbed surface measured by NMR. The results indicated that residues Thr34, Ala36, Asp39, and Trp68 from MpCP3 (Fig. 4C, left panel) and His92, Asn116, and Thr119 from MpCP5, among others (Fig. 4C, right panel), are likely directly involved in the sugar-protein interaction through polar and nonpolar contacts. To further confirm this finding, we double mutated MpCP3 residues Ala36 to a Thr and Asp39 to a Gly, as well as did a single Trp68-to-Tyr mutation and tested the wild-type and mutant proteins for NAG4 binding capacity as judged by shifting on the proteins' thermal melting points (Supplementary Fig. S4). Accordingly, all the MpCP3 mutations affected their interaction to NAG4. Similarly, we mutated MpCP5 Tyr88 to Ser, His92 to Ala, Asn116 to Lys, and Thr119 to either Ser or Ala. Only Asn116Lys mutation apparently increased protein affinity for NAG4, indicating that the MpCP5-NAG4 binding surface is rather large and likely involves the simultaneous interaction of more than one molecule.

\section{MpCP5 blocked the perception of NAG6 by the plant.}

It has been reported that chitin fragments generated by the action of plant chitinases against the fungus cell wall during the early stages of infection can act as MAMPs, eliciting immune responses in plants (Boller 1995; de Jonge et al. 2010). MpCP5 is expressed while the fungus is interacting with the living parts of the plant, when a host response to the pathogen attack is expected. In order to evaluate the functional significance of the NAG oligomer-MpCP5 interaction, we exposed tobacco plants to the chitin fragment NAG6 as well as NAG6 preincubated with MpCP5, and investigated, by quantitative polymerase chain reaction ( $\mathrm{qPCR}$ ), the expression of defense-related genes (Fig. 4D). As expected, plants responded to the presence of NAG6 by increasing expression of tpal (phenylalanine ammonia lyase), involved in phytoalexin synthesis pathway and SAR activation (Gayoso et al. 2010); nprl (nonexpresser of pathogenesis-related [PR] genes 1), a transcription factor pivotal for the activation of SAR (Dong 2004); and $p r-4 a$ and $p r-5$ genes, both described as displaying antifungal activity (Guevara-Morato et al. 2010; van Loon et al. 2006). The preincubation of MpCP5 with the NAG6 fragments reduced the response levels back to control (just buffer), suggesting that MpCP5 protein can help block plant defense response by scavenging released chitin fragments.

\section{The MpCP have neither glycolytic activity against nor bind to plant cell wall components.}

Similarly to CpCP and the bacterial expansin EXLX1, the $\mathrm{MpCP}$ present structural conservation with the catalytic domain found in family 45 of glycosyl hydrolases and in the MltA family of lytic transglycosylases (Supplementary Fig. S5) (de Oliveira et al. 2011; Kerff et al. 2008). Nevertheless, tests for hydrolytic activity of MpCP 1, 2, 3, and 5 against some common plant cell wall components and other polysaccharides, as well as cacao cell wall extract $(\mathrm{CCW})$, all proved negative (Fig. 5A). Given that MpCP3 and MpCP5 were shown to bind to the soluble tetrameric form of NAG, we questioned whether these proteins would be able to bind to insoluble chitin polymers via pull-down assay, therefore mimicking a possible interaction with the fungal cell wall. The pull-down assays were also performed against the $\mathrm{CCW}$. As described for the CpCP protein (Baccelli et al. 2013), MpCP 1, 2, 3, and 5 did not bind to the plant cell-wall (Fig. 5B) but they were all (on both soluble [Fig. 5C] and aggregated [data not shown] forms) pulled-down by chitin polymers, with MpCP3 apparently binding the strongest.

\section{MpCP2 and MpCP3 have a higher propensity to form soluble aggregates that induce thioflavin $\mathrm{T}$ fluorescence.}

The $\mathrm{MpCP}$ highly related protein $\mathrm{CpCP}$ resembles another class of fungal-secreted proteins known as hydrophobins (HPB), which have many distinct roles in fungal development and in pathogen-host interactions (Pazzagli et al. 2009; Whiteford and Spanu 2002). In this regard, we studied the MpCP1, MpCP2, $\mathrm{MpCP} 3$, and MpCP5 self-assembling properties. A range of 0.1 to $3 \mathrm{mM}$ for each $\mathrm{MpCP}$ was incubated for 30 days at $37^{\circ} \mathrm{C}$

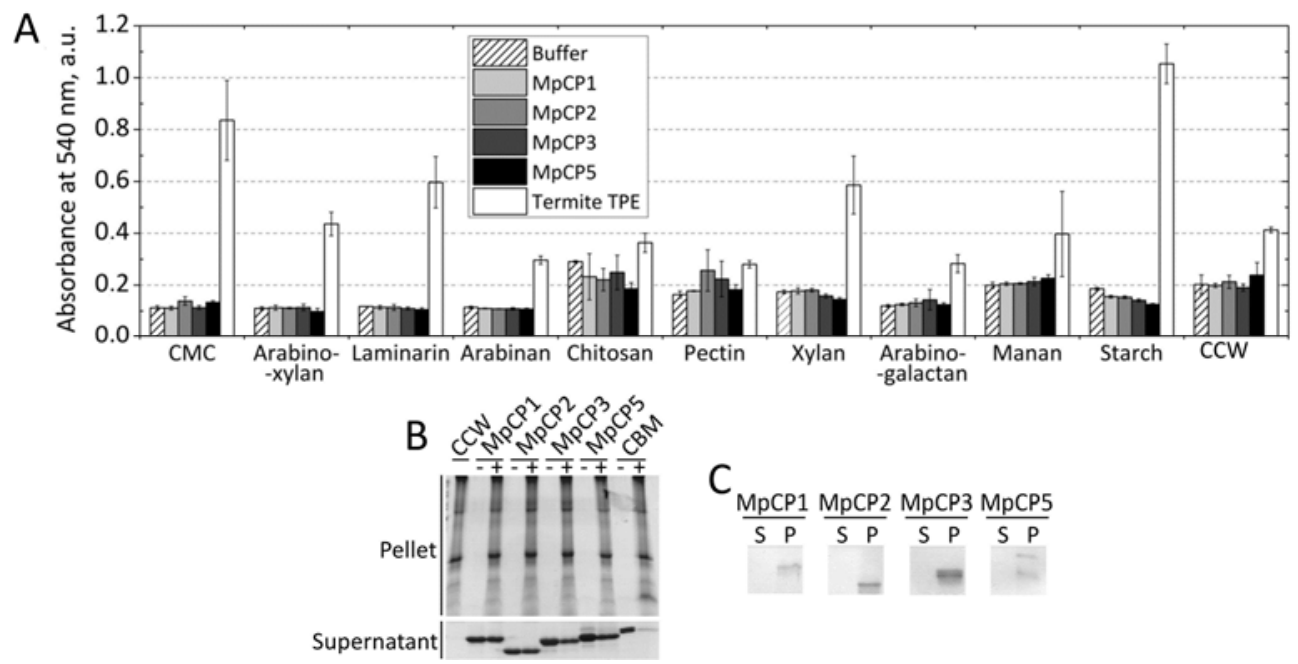

Fig. 5. Sugar hydrolysis and cacao cell wall or chitin binding assays. A, Colorimetric assay, with the substrate 3,5-dinitrosalicylic acid (DNS), evaluating the glycolytic activity of the recombinant $\mathrm{MpCP} 1,2,3$, and 5 against different substrates. No significant activity was detected for any MpCP analyzed, when compared with positive control termite total protein extract (TPE). B, Similarly, no relevant interaction between MpCP and cocoa-extracted cell wall (CCW) was detected in a pull-down assay, when compared with positive control family 3 carbohydrate-binding module (CBM3) from Bacillus subtilis. + and indicate the presence and absence of $\mathrm{CCW}$, respectively. C, All MpCP (soluble form) tested were pulled-down by chitin-insoluble polymers, with MpCP3 showing the highest levels of interaction. Chitin is one of the main components of the fungal cell wall. $\mathrm{S}=$ supernatant fraction and $\mathrm{P}=$ pellet fraction. 
under low $\mathrm{pH}$ treatment ( $\mathrm{pH} 3.0$ ), as previously described for the CpCP protein (Pazzagli et al. 2009), and the thioflavin T (ThT) fluorescence signal was monitored. The existence of a threshold concentration below which aggregation does not occur is an important feature associated with amyloid fibrils (Lomakin et al. 1996). The MpCP2's ThT fluorescence readings drastically increased (over 15 times compared with the control) from 0.4 to $0.8 \mathrm{mM}$ protein concentration (Fig. 6A). MpCP3 and MpCP5, although to a smaller extent, also induced significant ThT fluorescence at $0.8 \mathrm{mM}$ protein. Compared with the other analyzed $\mathrm{MpCP}, \mathrm{MpCP} 1$ showed low levels of ThT-positive aggregates only at greater than $1.5 \mathrm{mM}$ protein concentration. The initial aggregation step is commonly known to start from a partly unfolded monomeric intermediate which presents increased surface hydrophobicity (Murphy 2007). Accordingly, the fluorescence intensities of the probes 1,8-ANS and bis-ANS, two hydrophobic dyes that bind to the solvent-exposed hydrophobic surfaces, were greatly enhanced upon interaction with $0.8 \mathrm{mM}$ MpCP1, MpCP2, MpCP3, and MpCP5 aggregates (Fig. 6B).

In light of these results, we performed a time course study of protein aggregation of $0.8 \mathrm{mM} \mathrm{MpCP} 2$ and $\mathrm{MpCP} 3$ at $37^{\circ} \mathrm{C}$ in low $\mathrm{pH}$ solution. The kinetic curves of the ThT fluorescence intensity are consistent with a nucleation-dependent polymerization model commonly observed for proteins that can form amyloid fibrils (Lomakin et al 1996). Whereas MpCP2 took 3 days to reach a signal plateau (Fig. 6C), MpCP3 showed a similar pattern but only after 25 days of incubation.

\section{Biophysical and functional characterization of the soluble aggregates.}

The secondary structure changes accompanying MpCP aggregation (at a protein concentration of $0.8 \mathrm{mM}$ ) were analyzed by far-UV circular dichroism (CD) spectroscopy after 5, 10, and 20 days of low $\mathrm{pH}$ incubation at $37^{\circ} \mathrm{C}$. After as few as 5 days, it was possible to detect a loss of the MpCP1 native conformation and the acquisition of a random coil structure, with a negative band at $200 \mathrm{~nm}$ (Fig. 7A), suggesting protein unfolding, as further confirmed by NMR spectroscopy (Supplementary Fig. S6, left panel). Curiously, the highly ThT-responsive MpCP2, as well as MpCP3 and MpCP5, did not present characteristic random-coil spectra or a shift from $\alpha$-helix to $\beta$-sheet content, as commonly found in $\beta$-amyloid fibers. This is somewhat in agreement with a previous report, in which the $\mathrm{CpCP}$ did not display conformational changes corresponding to an increase in $\beta$-structure, being rather unfolded or acquiring a new secondary structure pattern (Pazzagli et al. 2009).

Globular proteins under equilibrium conditions may have at least two different partially folded conformations, the molten globule and its precursor, the pre-molten globule, both of which may potentially play a role as the crucial amyloidogenic species (Uversky and Fink 2004). The most characteristic feature of the amyloidogenic pre-molten globule CD spectra is a large negative ellipticity at $200 \mathrm{~nm}$ and low ellipticity in the vicinity of 222 $\mathrm{nm}$, with native or molten globule presenting a combination of opposite situations and the unfolded proteins showing the largest negative values at $200 \mathrm{~nm}$ and ellipticity in the vicinity of 222 nm close to zero (Uversky and Fink 2004). According to a survey of $C D$ spectra of several proteins captured on different states, the MpCP2, MpCP3, and MpCP5 CD profiling, as well as their MRE $[\theta]_{200} \times \operatorname{MRE}[\theta]_{222}$ combination, shows that the mild denaturing treatment likely brought the protein to a molten globule state (Fig. 7B), while MpCP1 positions closer to coordinates more characteristic of an unfolded state.

Dynamic light scattering analysis of $\mathrm{MpCP} 1,2,3$, and 5 before and after 15 days of incubation in low $\mathrm{pH}$ solution confirmed the formation of aggregates of protein (Fig. 7C). Because MpCP5 was one of the proteins with the smallest ThT signal, we further characterized its aggregation process by NMR. Twodimensional ${ }^{15} \mathrm{~N}$-HSQC spectra indicated that, after 4 days of incubation at $37^{\circ} \mathrm{C}$ at low $\mathrm{pH}$, the great majority of peaks either had a decreased intensity or disappeared, a clear indication of oligomerization process (Cavanagh et al. 2007). The filamentous nature of the aggregates was visually confirmed for MpCP2, by using transmission electron microscopy (Fig. 7D).

The $C$. platani $\mathrm{CP}$ self-aggregation correlates to a fragmentation process, as for some amyloid-like proteins which undergo self-assemblage after a cleavage of the polypeptide chain (Mishra et al. 2007; Pazzagli et al. 2009; Tsiroulnikov et al. 2006). The identification of the cleavage sites and aggregating peptides of MpCP 1, 2, 3, and 5 was done by mass spectrometry and is in clear accordance with what was described for CpCP (Pazzagli et al. 2009) (Supplementary Figs. S7 and S8; Supplementary Table S3).

Finally, we further investigated the biological relevance of the aggregation processes by assessing the capability of aggregated $\mathrm{MpCP} 2$ to loosen cellulose. Soluble $\mathrm{CpCP}$ and Pop1 were shown to fragment cellulosic substrates through a nonenzymatic mechanism (Baccelli et. al, 2013). We verified that aggregated $\mathrm{MpCP} 2$ (but not its soluble monomeric form) promotes cellulose fragmentation, which may implicate a role of this protein's aggregates during the interaction of $M$. perniciosa with the cocoa (fixation to the substrate and nutrient acquisition) (Fig. 7E). Aggregated $\mathrm{MpCP} 2$ also potentiated the growth the $M$. perniciosa basidiospore's germination tube (Fig. 7F), a phenomenon which may be related to the fungus's
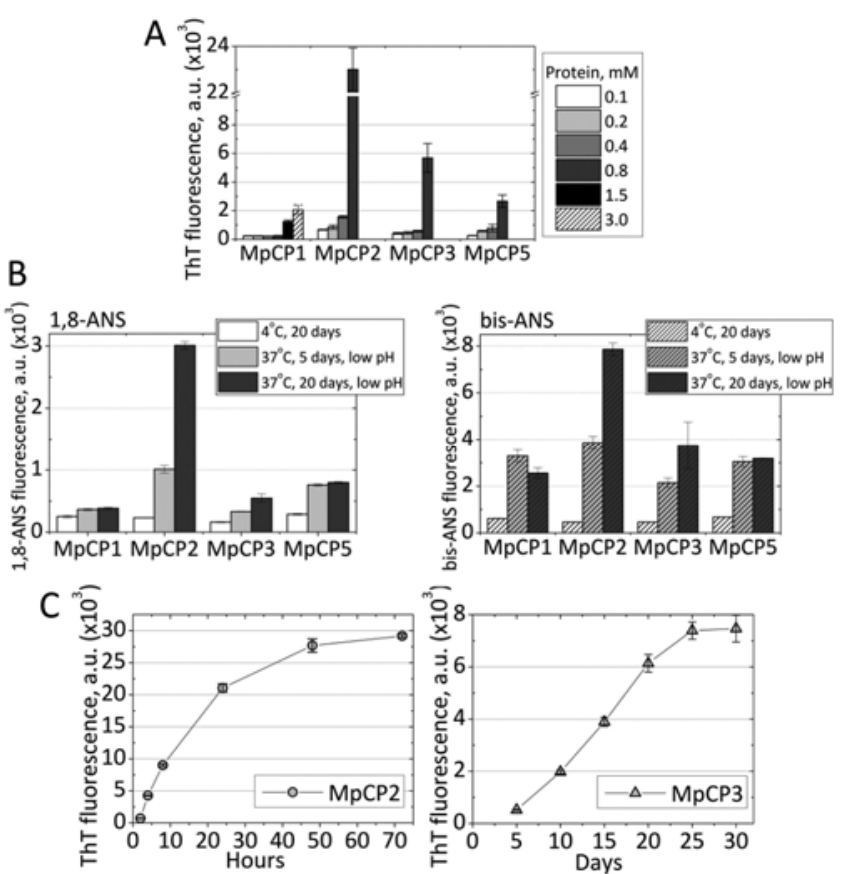

Fig. 6. Evaluation of self-aggregation capability. A, Detection of the fluorescence signal induced upon the binding of thioflavin $\mathrm{T}$ (ThT) against increasing concentrations of $\mathrm{MpCP}$ incubated at $37^{\circ} \mathrm{C}$ and low $\mathrm{pH}$ for 30 days. Data allowed the determination of an amyloid-like self-aggregation behavior for $\mathrm{MpCP} 2,3$, and 5 at threshold concentrations between 0.4 and $0.8 \mathrm{mM}$ protein. MpCP1 displayed the same behavior, although only at concentrations beyond $1.5 \mathrm{mM}$, similarly to cerato-platanin from Ceratocystis platani (CpCP) (Pazzagli et al. 2009). B, The signal measured upon the binding of the dyes 1,8-ANS and bis-ANS to MpCP 1, 2, 3, and 5, indicating the hydrophobic nature of the aggregates. C, Time course analysis of the self-assembly of $0.8 \mathrm{mM} \mathrm{MpCP} 2$ and $\mathrm{MpCP} 3$ at $37^{\circ} \mathrm{C}$ and low $\mathrm{pH}$, as monitored by ThT fluorescence, shows a much quicker dynamics of aggregation for $\mathrm{MpCP} 2$, which reaches equilibrium after only $50 \mathrm{~h}$, compared with 25 days required for MpCP3. All the experiments were performed in triplicate. 
hyphal development. Curiously, MpCP2 is highly expressed in the in-vitro-grown mycelium and in the fungus of infected fruit (Fig 1B and C), situations where fast growth is propitiated by the nutrient-rich environment.

\section{DISCUSSION}

M. perniciosa, a fungus with a hemibiotrophic lifestyle, presents 12 copies of CP-coding sequences in its genome. Different genetic evolutionary models predict an expansion in a gene's copy number before their specialization or the rise of new functions, also accounting for an overlap of functions due to a momentary intermediate state of specialization (Bergthorsson et al. 2007). In this work, we showed that the MpCP (1 to 12) are expressed at particular stages of the WBD and, based on our data and on the literature above, we reason that $M$. perniciosa evolved different proteins to perform different, specialized roles during its hemibiotrophic life cycle.
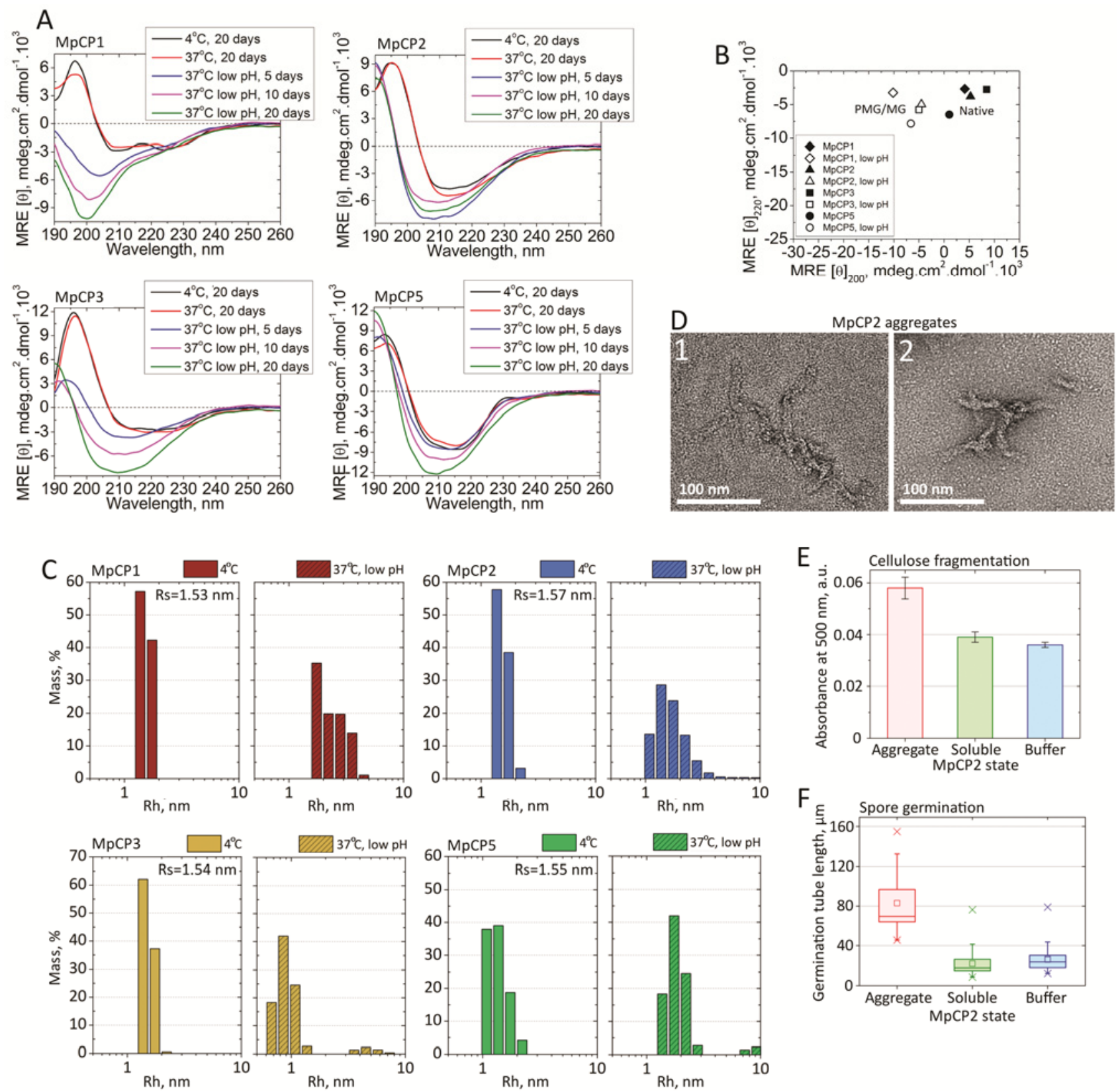

Fig. 7. Biophysical characterization of the aggregates. A, Far-UV circular dichroism (CD) allowed the tracking of the changes in secondary structure of the $\mathrm{MpCP}$ required for self-assembling (at $0.8 \mathrm{mM}$ concentration). Upon incubation at low $\mathrm{pH}$ and high temperature, MpCP1 assumed a completely unfolded structure (with a negative band at $200 \mathrm{~nm}$ ), whereas MpCP 2, MpCP3, and MpCP5 acquired a closer to zero band at $200 \mathrm{~nm}$ and more negative ellipticity at $222 \mathrm{~nm}$. No difference was observed in the CD spectra for the MpCP between native initial state ( 0 days) and after 20 days of incubation at $4^{\circ} \mathrm{C}$ (data not shown). B, MRE $[\theta]_{200} \times \operatorname{MRE}[\theta]_{222}$ combination extracted from the $4^{\circ} \mathrm{C}(\mathrm{pH} 7.2)$ and $37^{\circ} \mathrm{C}$ (at low pH) spectra for all proteins. The definition of a native, pre-molten globule and molten globule regarding the combined mean residue ellipticity at 200 and $222 \mathrm{~nm}$ was taken as revised (Uversky and Fink 2004). C, Dynamic light scattering data showing the aggregation process as defined by a shift in the Stokes radius after incubation at $37^{\circ} \mathrm{C}$ and low $\mathrm{pH}$. Theoretical values for the Stokes radii $\left(R_{\mathrm{s}}\right)$, calculated using Hydropro (Ortega et al 2011), were 1.83, 1.76, 1.73, and $1.95 \mathrm{~nm}$ for monomeric MpCP 1, 2, 3, and 5, respectively. D, Micrographs 1 and 2, obtained by negative stain electron microscopy, depict the filamentous nature of MpCP2 aggregates $(0.8 \mathrm{mM}, 20$ days of incubation at low $\mathrm{pH}) . \mathbf{E}$, Cellulose-loosening activity was detected for aggregated MpCP2 but not its soluble monomeric counterpart. F, Aggregated MpCP2 also promotes Moniliophthora perniciosa basidiospore germination tube growth. Aggregated $n=12$, soluble $n=37$, and buffer $n=34$. 
The biotrophic stage of $M$. perniciosa is unusually extended, lasting for 2 to 3 months in the plant's infected tissue and creating a nutrient sink to the infection site, so that the host is disadvantaged but not killed (Scarpari et al. 2005). During this stage, preventing the elicitation of the host's immune response is key for fungus survival. None of the purified MpCP caused necrotic symptoms or phytoalexin induction on tobacco leaves injected with these proteins (Supplementary Fig. S9), in accordance with results obtained with $\mathrm{CtCP} 1$, the $\mathrm{CP}$ from Colletotrichum truncatum, another hemibiotrophic pathogen, whose protein also did not induce defense responses in planta (Bhadauria et al. 2011). This may suggest an evolutionary pressure to reduce the defense-eliciting ability of $\mathrm{CP}$ proteins in hemibiothrophic life styles. However, our findings are in contrast to a previous report (Zaparoli et al. 2009), which showed the necrotic activity of MpCP1 on tobacco and cocoa leaves. It is possible that the observed differences are due to the presence of bacterial contaminants on their sample, because we added a further purification step in our protein preparation.

Gene transcripts of $\mathrm{MpCP} 4, \mathrm{MpCP} 5$, and $\mathrm{MpCP} 11$ (from the cluster Mper1 of the presented phylogenetic tree) were exclusively detected in the slow-growing biotrophic phase, when the fungus develops in the apoplast of the plant and where the pathogen-host survival battle is established. Using NMR, we have shown that recombinant MpCP5 binds to NAG4 with the highest affinity via a previously unidentified binding site. This interface, in MpCP5, is located around a much shorter $\beta$-hairpin formed between sheets $\beta 3$ and $\beta 4$, when compared with MpCP 1 and 2. The large protein surface disturbed by NAG4 opens the possibility that either the protein goes through a profound conformational change due to the sugar interaction or multiple binding sites are existent. Tobacco gene expression data showed that MpCP5 is capable of blocking the plant response defense to the chitin fragment NAG6, a potent defense elicitor released during fungal colonization (Boller 1995). Taken together, these results create a potential link between MpCP5's biotrophic phase expression, its NAG oligomer-binding property, and its capacity for suppressing the plant immune response. Likewise, MpCP4 and MpCP11 may also be important in protecting the fungus against the cacao, because most of the key residues we identified for NAG4 binding in MpCP5 are conserved on these proteins. Thus far, the $\mathrm{CP}$ have been implicated as fungal elicitors or effectors, either promoting the virulence of pathogenic fungi or enhancing the plant's resistance against other microorganisms (Djonović et al. 2007; Frías et al. 2011, 2013; Jeong et al. 2007; Pazzagli et al. 1999; Vargas et al. 2008). Although de Oliveira and colleagues (2011) have hypothesized that CP might act as defense suppressors by scavenging free chitin fragments, we present here experimental evidence which suggests such a thing, bringing a potential new feature to this class of protein.

The MpCP belonging to the phylogenetic cluster Mper2 (MpCP 2, 3, 7, 8, 10, and 12), positioned together with homologues from the saprotrophic $C$. campanella and their gene transcripts, were detected during the late and necrotic stages of the cacao fruit infection, as well as in the in-vitro-grown mycelium. Worthy of note, MpCP3 was previously detected in our laboratory in an in-vitro-grown biotrophic-like mycelium (Rincones et al. 2008), and the gene fragment was identified as CERAT then. Even though the biotrophic-like mycelium used by Rincones and colleagues presented biotrophic morphological characteristics (thick, monokaryotic hyphae without clamp connections), further studies in our laboratory showed that it also expressed some of the genes typically found in the necrotrophic stage of the disease (data not shown), probably due to the use of cocoa extract-containing conditions (nutrients which are usually only available during the necrotrophic phase).
NMR data showed that MpCP3 also binds to NAG4; however, with a lower affinity when compared with MpCP5. MpCP3 shares an NAG4-binding surface similar to the one previously described for $\mathrm{CpCP}$, as confirmed by site-directed mutagenesis and thermal shift assays. Computational docking allowed the determination of an interface involving the diametrically opposed loops between $\beta 2$ and $\beta 3$ (which is much larger than its equivalent in MpCP5) and helices $\alpha 1$ and $\alpha 2$. The sequence composition of these loops in MpCP3 is not only distinct from those in MpCP5 but also diverges between MpCP1 and 2, thus explaining why the later two did not bind significantly to NAG4. The three residues directly involved in MpCP3 binding to NAG4 (Ala36, Asp39, and Trp68) are fully conserved on both $\mathrm{MpCP} 7$ and $\mathrm{MpCP} 9$, suggesting that these proteins also bind to NAG4. It is worth noting that, similarly to MpCP3, MpCP7 is expressed on the rotten, infected fruit or plant and lab-cultivated fungus, both representative of the fastgrowing necrotrophic stage.

The CP from Ceratocystis platani and C. populicola have been shown to self-aggregate under mild-denaturing conditions, such as acetic acid and 2,2,2-trifluoroethanol solution, as well as exposure to hydrophobic surfaces (Martellini et al. 2012; Pazzagli et al. 2009). The protein Epl1 presented spontaneous quick assembling but no further characterization of the aggregates was performed (Frischmann et al. 2013). Another protein family present in fungi that is able to enhance ThT fluorescence after its assemblage is the HPB (Wösten and de Vocht 2000). Rodlets formed by aggregated HPB first lower the surface tension at the water-air interface and are important for fungal development and virulence by creating amphipathic layers that facilitate hyphal growth and adhesion, as well as the formation of haustoria and fruiting bodies. Similarly to the $\mathrm{CpCP}$ and MpCP, HPB have intramolecular disulfide bonds, are secreted as monomers, and self-aggregate under favorable conditions (Whiteford and Spanu 2002). All four tested MpCP were capable of self-aggregation after incubation in low-pH solution. MpCP1, the one with the slowest aggregation kinetics, presented levels comparable with CpCP (Pazzagli at al. 2009), while $\mathrm{MpCP} 2$, followed by $\mathrm{MpCP} 3$, were the most responsive, as qualitatively judged by the kinetics curves of ThT fluorescence.

In physiological environments, where many processes are dictated by interface phenomena, the presence of a surface (such as the host cuticle, cell wall, or membrane) may provide the necessary perturbation to induce the conversion from the soluble conformation to the self-assembling conformation (Martellini et al. 2012; Moores et al. 2011; Murphy 2007). The native globular structure of several proteins has been shown to be destabilized to pre-molten or molten globule-like structures by a myriad of different agents (e.g., high temperatures, organic solvents, low or high $\mathrm{pH}$, low to mild concentrations of strong denaturants, and others), which may significantly accelerate the rate of fibril formation (Uversky and Fink 2004). Another aspect of $\mathrm{CpCP}$ and other aggregating proteins mirrored by the $\mathrm{MpCP}$ is the self-cleavage process as a prerequisite for the process (Mishra et al. 2007; Pazzagli et al. 2009; Tsiroulnikov et al. 2006), probably enabling the exposure of hydrophobic regions of the protein that can then establish the first intermolecular contacts needed for self-assembling.

We propose that the chitin-binding property of both MpCP2 and $\mathrm{MpCP} 3$, along with their and MpCP1's self-aggregation characteristic (all proteins expressed during fast-growing phases of the fungus), very likely facilitates the process of hyphal growth, fruiting body formation, and substrate adhesion. Furthermore, MpCP2 aggregates but not the soluble protein revealed expansin characteristics because it was able to promote cellulose fragmentation. Plant cell wall (rich in cellulose) loosening activity may be important for host colonization during 
fungal infection but also for growth on dead plant tissue and nutrient acquisition. Moreover, MpCP2 aggregates were also shown to contribute to germination tube formation and are likely to be important for fungus development. Although not tested, the MpCP3 binding surface to NAG4 (which is distinct from the MpCP5 surface) may be important for chitin binding (this isoform was the one with higher qualitative affinity to chitin), fungus cell wall remodeling, and growth.

$M$. perniciosa presents a well-characterized yet complex lifestyle (Meinhardt et al. 2008). The existence of a biotrophic phase, followed by the progression to a necrotrophic stage, requires the fungus to thrive at the most diverse physiological environments inside its host. Consistently, we propose, for the first time, a differentiation model for $\mathrm{CP}$ in an organism, based on protein functional specialization. $M$. perniciosa is the only basidiomycete phytopathogen among all previously studied CP-bearing organisms and, overall, the results provided in this work may help constitute a useful platform for compound design which can block the protein activity and help to compose a combat approach against the disease.

\section{MATERIALS AND METHODS}

\section{Genome survey.}

To identify $\mathrm{CP}$ orthologous genes in the $M$. perniciosa biotype C genome (Mondego et al. 2008), we searched for sequences classified within the InterPro ID IPR010829 (Hunter et al 2012). Five genes (MpCP1 to MpCP5) had been previously described (Zaparoli et al. 2009). Seven new ones were further identified and named MpCP6 to MpCP12. The open reading frames of all $\mathrm{MpCP}$ from $M$. perniciosa biotype $\mathrm{C}$ genes were confirmed by cDNA sequencing and deposited at GenBank (accession numbers provided above). To identify the CP's sequences from the isolate MCA2977 of M. roreri and the isolate APS1 of $M$. perniciosa biotype S, we used genomic and RNA-seq data (unpublished data). CP's introns were found through the alignment between RNA-seq and genomicderived sequences of the $M$. perniciosa biotype S and M.roreri. Because there is no expression data for Crinipellis campanella, its CP's genomic sequences were evaluated for intron presence with the aid of the software Augustus Gene Finder v2.3 (Stanke et al. 2004) trained with genes of Coprinopsis cinerea and expressed sequence tags from M. perniciosa, as previously described (Mondego et al. 2008). The software SignalP 4.0 (Petersen et al. 2011) was used to predict the presence of secretion signal peptide in all of the encoded proteins.

\section{RNA-seq.}

The reproductive structures of $M$. perniciosa (basidiomata) were produced following the procedures described (Pires et al. 2009) and were used to collect basidiospores directly in the collection solution ( $16 \%$ glycerol, $0.01 \mathrm{M}$ morpholineethanesulfonic acid and $0.01 \%$ Tween, $\mathrm{pH}$ 6.1), as described elsewhere (Frias et al. 1995). Theobroma cacao var. Comum was cultivated in a greenhouse under controlled temperature and humidity conditions (from 22 to $28^{\circ} \mathrm{C}$ and greater than $50 \%$, respectively). Two-month-old seedlings were infected with $M$. perniciosa basidiospores, as previously described (Frias et al. 1995), and RNA was extracted from infected parts of the plant at representative time points of the disease, from the green broom to complete necrosis. Infected fruit from $T$. cacao var. comum trees were collected in a cacao farm located in Ilhéus, Brazil. Three stages of the disease were analyzed: early stage (which is characterized by disordered fruit ripening), partial necrosis stage, and rotten fruit stage. The seed and pods of each fruit were collected independently for RNA extraction. For RNA extraction of $M$. perniciosa basidiospores, $1 \mathrm{ml}$ of a suspension containing approximately $10^{7}$ spores $/ \mathrm{ml}$ was gently centrifuged at $1,000 \times g$ for $5 \mathrm{~min}$ to precipitate the basidiospores, which were resuspended in $1 \mathrm{ml}$ of collection solution (which prevents the germination) or resuspended in $1 \mathrm{ml}$ of sterile water (to allow germination). Both aliquots were transferred to small beakers and incubated at $28^{\circ} \mathrm{C}$ and $120 \mathrm{rpm}$ for $4 \mathrm{~h}$. The germination of the basidiospores was microscopically verified prior to RNA extraction. In-vitro-grown mycelium or mature basidiomata were pooled and used for RNA extraction.

For each sample, $10 \mu \mathrm{g}$ of total RNA were used to prepare the mRNA-seq library according to the protocol provided by Illumina. Library quality control and quantification were performed with the Experion Automated Electrophoresis System (Bio-Rad, Munich) and the Qubit fluorometer (Invitrogen, Carlsbad, CA, U.S.A.), respectively. Each library was sequenced in one lane of an Illumina Genome Analyzer IIx sequencer to produce 36-bp single-end reads. The RNA-seq reads were aligned against a reference comprising 17,008 gene models of $M$. perniciosa using the program Bowtie (Langmead et al. 2009). The alignment was performed by allowing up to two mismatches and excluding reads that mapped to more than one position in the reference. The number of reads mapped to each gene was divided by the size of the gene (in kilobases) and then normalized by the total mapped reads of the library (in millions of reads). Thus, the expression value of each gene was given in mapped reads to a gene per kilobase per million of total mapped reads, so that the level of expression of genes within the same library and in different libraries are comparable (Mortazavi et al. 2008). This data is part of the WBD Transcriptome Atlas (unpublished data).

\section{Heterologous MpCP production.}

$\mathrm{MpCP}$ coding genes were amplified from a cDNA library prepared from $M$. perniciosa, as described elsewhere (Zaparoli et al. 2009). The constructs were cloned into a modified version of pETSUMO (Invitrogen) and transformed into E. coli Origami 2 (Merck, Darmstadt, Germany) chemically competent cells. The final constructs spanned residues 20 to 145 (MpCP1), 17 to 140 (MpCP2), 15 to 135 (MpCP3), and 22 to 156 (MpCP5). For MpCP purification, the transformed bacteria were lysed and the clarified soluble fraction purified by a two-step procedure, starting with immobilized metal ion affinity chromatography using the $\mathrm{Co}^{2+}$-charged TALON resin (BD Biosciences, Rutherford, NJ, U.S.A.), equilibrated with $50 \mathrm{mM}$ Tris- $\mathrm{HCl}, \mathrm{pH} 8.5$, and $150 \mathrm{mM} \mathrm{NaCl}$. The resin was washed extensively with this solution and then incubated overnight at room temperature with the appropriate amount of the protease ULP-1 for His-SUMO tag removal. The cleaved protein was eluted from the resin and loaded onto the Superdex $75 \mathrm{HR}$ 10/30 gel filtration column (GE Healthcare, Piscataway, NJ, U.S.A.) equilibrated in $50 \mathrm{mM}$ Tris- $\mathrm{HCl}, \mathrm{pH} 8.5$, and $150 \mathrm{mM}$ $\mathrm{NaCl}$. Several attempts to produce soluble MpCP4 did not succeed well. The eluted protein was concentrated to the required concentration as judged by $\mathrm{UV}_{280 \mathrm{~nm}}$ absorption and calculated coefficient extinction value as estimated through the primary sequence and the ExPASy ProtParam tool (Gasteiger et al. 2005), and used for crystallization screens as well as functional assays.

\section{X-ray crystallography.}

Crystals were grown using the conventional sitting drop, vapor diffusion method in the following conditions: MpCP1: 0.1 M sodium acetate ( $\mathrm{pH} 4.5), 20 \%$ polyethylene glycol (PEG) 1000, and 0.2 M zinc acetate; MpCP2: 0.1 M sodium acetate ( $\mathrm{pH} 4.6)$ and 8\% PEG 4000; MpCP3: $0.1 \mathrm{M}$ bis-Tris propane ( $\mathrm{pH} 7.0)$ and $1.5 \mathrm{M}$ ammonium tartrate; and MpCP5: $0.1 \mathrm{M}$ sodium acetate ( $\mathrm{pH} 5.5), 5 \%$ PEG 400, and 18\% PEG 
3350. X-ray diffraction datasets were collected at beamlines D03B-MX1 and W01B-MX2 at the Brazilian National Synchrotron Laboratory (LNLS). All data were integrated using Mosflm (Leslie 1992) and scaled with SCALA (Evans 2006). MpCP1 was solved by Sulfur-SAD using SHELX (Sheldrick 2010) and the first set of phases of MpCP2 and MpCP3 were obtained by the molecular replacement with MrBUMP (Keegan and Winn 2008), using the MpCP1 monomer as the search model. The initial set of phases of MpCP5 was obtained using Phaser (McCoy et al. 2007) and the protein Sm1 from T. virens as the search model (PDB ID: 3M3G). Positional and B-factor refinement cycles, as well as solvent modeling, were performed with Refmac (Vagin et al. 2004) followed by visual inspection using COOT (Emsley et al 2010).

\section{NMR spectroscopy.}

${ }^{15} \mathrm{~N}$ - and ${ }^{13} \mathrm{C} /{ }^{15} \mathrm{~N}$-labeled MpCP proteins were produced and purified, were dialyzed against a solution containing $20 \mathrm{mM}$ $\mathrm{Na}_{2} \mathrm{HPO}_{4}-\mathrm{NaH}_{2} \mathrm{PO}_{4}(\mathrm{pH} 7.2)$ and $50 \mathrm{mM} \mathrm{NaCl}$, and then, $10 \%$ $\mathrm{D}_{2} \mathrm{O}$ was added for NMR experiments. NMR spectra were recorded on a Varian Inova 600-MHz spectrometer equipped with a cryogenic probe. The spectra were processed with NMRPipe/NMRDraw (Delaglio et al. 1995) and analyzed with NMRView (Johnson and Blevins 1994). The backbone assignments of MpCP3 and MpCP5 were determined using the three-dimensional experiments $\mathrm{HNCACB}, \mathrm{CBCA}(\mathrm{CO}) \mathrm{NH}$, HNCO, and HN(CA)CO (Ikura et al. 1990; Grzesiek and Bax 1993; Wittekind and Mueller 1993; Yamazaki et al 1994) and the graphical interface Smartnotebook (Slupsky et al. 2003). Titrations of ${ }^{15} \mathrm{~N}$-labeled MpCP proteins with NAG and NAG4 were followed by the recording of the two-dimensional ${ }^{15} \mathrm{~N}$ HSQC spectra. For more details on the techniques described and other techniques.

The following procedures are described in the Supplementary Text: phylogenetic reconstruction; crystallization, X-ray crystallography data collection, and processing; structure solution and refinement; NMR sample preparation; NAG titration NMR experiment; NAG docking to MpCP3 and MpCP5, mutagenesis- and fluorescence-based thermal shift assays; qPCR; cacao cell wall extraction; pull-down assays; ThT, 1,8ANS, and bis-ANS fluorescence measurements; cellulose fragmentation; spore germination; CD spectroscopy; identification of native $\mathrm{MpCP}$ by mass spectrometry; transmission electron microscopy; studies of protein cleavage associated to selfassembling by mass spectrometry; and injection of MpCP in tobacco leaves.

\section{ACKNOWLEDGMENTS}

This work was supported by FAPESP grant 2010/51884-8 (to A. L. B. Ambrosio), FAPESP fellowships 2010/14504-2 (to M. R. O. Barsottini) and 2010/51891-4 (to J. F. de Oliveira), and CNPq fellowship 400796/2012-0 (to A. Cassago). We thank LNBio for financial support and access to all facilities (MAS, LPP, LEC, Robolab, and NMR), LNNano for accessibility to LME as well as the staff of the X-ray crystallography beamlines (D03B-MX1 and W01B-MX2 at LNLS) used in this work, Dr. A. Girasole for technical support, and G. L. Fiorin for promptly providing fungal material used in this study. M. R. Barsottini performed heterologous protein production and purification, polysaccharide interaction assays, basidiospore germination assays, biophysical and biochemical characterizations, in planta defense response experiments, and edited the manuscript. J. F. Oliveira performed heterologous protein production and purification, X-ray crystallography and structure refinement, biophysical and biochemical characterizations, NMR experiments, identified NMR spectra peaks, and edited the manuscript. D. Adamoski performed phylogenetic relationship construction and analysis and executed qPCR experiments. P. J. Teixeira and G. A. Pereira designed and performed RNAseq experiments. P. F. Prado and H. O. Tiezzi performed heterologous protein production and purification. M. L. Sforça and A. C. Zeri designed, performed, and interpreted NMR experiments. A. Cassago and R. V. Portugal performed transmission electron microscopy of MpCP2. P. S. Oliveira performed docking experiments. S. M. Dias designed biophysical and biochemical characterizations, interpreted the data, and edited the manuscript. A. L. Ambrosio designed biophysical and biochemical characterizations, designed and performed X-ray crystallography and structure refinement, interpreted the data, and edited the manuscript.

\section{LITERATURE CITED}

Aime, M., and Phillips-Mora, W. 2005. The causal agents of witches' broom and frosty pod rot of cacao (chocolate, Theobroma cacao) form a new lineage of Marasmiaceae. Mycologia 97:1012-1022.

Baccelli, I., Comparini, C., Bettini, P., Martellini, F., Ruocco, M., Pazzagli, L., Bernardi, R., and Scala, A. 2012. The expression of the cerato-platanin gene is related to hyphal growth and chlamydospores formation in Ceratocystis platani. FEMS (Fed. Eur. Microbiol. Soc.) Microbiol. Lett. 327:155-163.

Baccelli, I., Luti, S., Bernardi, R., Scala, A., and Pazzagli, L. 2013. Cerato-platanin shows expansin-like activity on cellulosic materials. Appl. Microbiol. Biotechnol. Published online.

Bergthorsson, U., Andersson, D., and Roth, J. 2007. Ohno's dilemma: Evolution of new genes under continuous selection. Proc. Natl. Acad. Sci. U.S.A. 104:17004-17009.

Bhadauria, V., Banniza, S., Vandenberg, A., Selvaraj, G., and Wei, Y. 2011. EST mining identifies proteins putatively secreted by the anthracnose pathogen Colletotrichum truncatum. BMC Genomics 12:327.

Boddi, S., Comparini, C., Calamassi, R., Pazzagli, L., Cappugi, G., and Scala, A. 2004. Cerato-platanin protein is located in the cell walls of ascospores, conidia and hyphae of Ceratocystis fimbriata f. sp. platani. FEMS (Fed. Eur. Microbiol. Soc.) Microbiol. Lett. 233:341-346.

Boller, T. 1995. Chemoperception of Microbial Signals in Plant Cells. Annu. Rev. Plant Physiol. 46:189-214.

Carresi, L., Pantera, B., Zoppi, C., Cappugi, G., Oliveira, A., Pertinhez, T., Spisni, A., Scala, A., and Pazzagli, L. 2006. Cerato-platanin, a phytotoxic protein from Ceratocystis fimbriata: Expression in Pichia pastoris, purification and characterization. Protein Expres. Purif. 49:159167.

Cavanagh, J., Fairbrother, W., Palmer, A., III, Rance, M., and Skelton, N. 2007. Protein NMR Spectroscopy: Principles and Practice. Academic Press, San Diego, CA, U.S.A.

Comparini, C., Carresi, L., Pagni, E., Sbrana, F., Sebastiani, F., Luchi, N., Santini, A., Capretti, P., Tiribilli, B., Pazzagli, L., Cappugi, G., and Scala, A. 2009. New proteins orthologous to cerato-platanin in various Ceratocystis species and the purification and characterization of ceratopopulin from Ceratocystis populicola. Appl. Microbiol. Biot. 84:309322.

de Jonge, R., van Esse, H., Kombrink, A., Shinya, T., Desaki, Y., Bours, R., van der Krol, S., Shibuya, N., Joosten, M., and Thomma, B. 2010. Conserved fungal LysM effector Ecp6 prevents chitin-triggered immunity in plants. Science 329:953-955

Delaglio, F., Grzesiek, S., Vuister, G., Zhu, G., Pfeifer, J., and Bax, A. 1995. NMRPipe: A multidimensional spectral processing system based on UNIX pipes. J. Biomol. NMR 6:277-293.

de Oliveira, A., Gallo, M., Pazzagli, L., Benedetti, C., Cappugi, G., Scala, A., Pantera, B., Spisni, A., Pertinhez, T., and Cicero, D. 2011. The structure of the elicitor cerato-platanin $(\mathrm{CP})$, the first member of the $\mathrm{CP}$ fungal protein family, reveals a double $\Psi \beta$-barrel fold and carbohydrate binding. J. Biol. Chem. 286:17560-17568.

Desender, S., Andrivon, D., and Val, F. 2007. Activation of defence reactions in Solanaceae: Where is the specificity? Cell Microbiol. 9:21-30.

Djonović, S., Vargas, W. A., Kolomiets, M. V, Horndeski, M., Wiest, A., and Kenerley, C. M. 2007. A proteinaceous elicitor Sm1 from the beneficial fungus Trichoderma virens is required for induced systemic resistance in maize. Plant Physiol. 145:875-889.

Dong, X. 2004. NPR1, all things considered. Curr. Opin. Plant Biol.' 7:547-552.

Emsley, P., Lohkamp, B., Scott, W., and Cowtan, K. 2010. Features and development of Coot. Acta Crystallogr. D 66:486-501.

Evans, H. 2007. Cacao diseases-the trilogy revisited. Phytopathology 97:1640-1643.

Evans, P. 2006. Scaling and assessment of data quality. Acta Crystallogr. D 62:72-82.

Fontana, F., Santini, A., Salvini, M., Pazzagli, L., Cappugi, G., Scala, A. Durante, M., and Bernardi, R. 2008. Cerato-platanin treated plane leaves restrict Ceratocystis platani growth and overexpress defencerelates genes. J. Plant Pathol. 90:293-304.

Frias, G. A., Purdy, L. H., and Schmidt, R. A. 1995. An inoculation method for evaluating resistance of cacao to Crinipellis perniciosa. 
Plant Dis. 79:787-791.

Frías, M., González, C., and Brito, N. 2011. BcSpl1, a cerato-platanin family protein, contributes to Botrytis cinerea virulence and elicits the hypersensitive response in the host. New Phytol. 192:483-495.

Frías, M., Brito, N., and González, C. 2013. The Botrytis cinerea ceratoplatanin $\mathrm{BcSpl} 1$ is a potent inducer of systemic acquired resistance (SAR) in tobacco and generates a wave of salicylic acid expanding from the site of application. Mol. Plant Pathol. 14:191-196.

Frischmann, A., Neudl, S., Gaderer, R., Bonazza, K., Zach, S., Gruber, S., Spadiut, O., Friedbacher, G., Grothe, H., and Seidl-Seiboth, V. 2013. Self-assembly at air/water interfaces and carbohydrate binding properties of the small secreted protein EPL1 from the fungus Trichoderma atroviride. J. Biol. Chem. 288:4278-4287.

Gasteiger, E., Hoogland, C., Gattiker, A., Duvaud, S., Wilkins, M. R., Appel, R. D., and Bairoch, A. 2005. Protein identification and analysis tools on the ExPASy server. Pages 571-607 in: The Proteomics Protocols Handbook. J. M. Walker, ed. Humana Press, Totowa, NJ, U.S.A.

Gayoso, C., Pomar, F., Novo-Uzal, E., Merino, F., and De Ilárduya, O. M. 2010. The Ve-mediated resistance response of the tomato to Verticillium dahliae involves $\mathrm{H}_{2} \mathrm{O}_{2}$, peroxidase and lignins and drives PAL gene expression. BMC Plant Biol. 10:232.

Grzesiek, S., and Bax, A. 1993. Amino acid type determination in the sequential assignment procedure of uniformly ${ }^{13} \mathrm{C} /{ }^{15} \mathrm{~N}$-enriched proteins. J. Biomol. NMR 3:185-204.

Guevara-Morato, M. A., De Lacoba, M. G., García-Luque, I., and Serra, M. T. 2010. Characterization of a pathogenesis-related protein 4 (PR-4) induced in Capsicum chinense L3 plants with dual RNase and DNase activities. J. Exp. Bot. 61:3259-3271.

Hall, N., Keon, J., and Hargreaves, J. A. 1999. A homologue of a gene implicated in the virulence of human fungal diseases is present in a plant fungal pathogen and is expressed during infection. Physiol. Mol. Plant. Pathol. 55:69-73.

Holm, L., and Rosenström, P. 2010. Dali server: Conservation mapping in 3D. Nucleic Acids Res. 38:W545-W549.

Hunter, S., Jones, P., Mitchell, A., Apweiler, R., Attwood, T. K., Bateman, A., Bernard, T., Binns, D., Bork, P., Burge, S., de Castro, E., Coggill, P., Corbett, M., Das, U., Daugherty, L., Duquenne, L., Finn, R. D., Fraser, M., Gough, J., Haft, D., Hulo, N., Kahn, D., Kelly, E., Letunic, I., Lonsdale, D., Lopez, R., Madera, M., Maslen, J., McAnulla, C., McDowall, J., McMenamin, C., Mi, H., Mutowo-Muellenet, P., Mulder, N., Natale, D., Orengo, C., Pesseat, S., Punta, M., Quinn, A. F., Rivoire, C., Sangrador-Vegas, A., Selengut, J. D., Sigrist, C. J., Scheremetjew, M., Tate, J., Thimmajanarthanan, M., Thomas, P. D., Wu, C. H., Yeats, C., and Yong, S. Y.2012. InterPro in 2011: New developments in the family and domain prediction database. Nucleic Acids Res. 40:D306D312.

Ikura, M., Kay, L., and Bax, A. 1990. A novel approach for sequential assignment of ${ }^{1} \mathrm{H},{ }^{13} \mathrm{C}$, and ${ }^{15} \mathrm{~N}$ spectra of larger proteins: Heteronuclear triple-resonance three-dimensional NMR spectroscopy. Application to calmodulin. Biochemistry 29:4659-4667.

Jeong, J. S., Mitchell, T. K., and Dean, R. A. 2007. The Magnaporthe grisea snodprot1 homolog, MSP1, is required for virulence. FEMS (Fed. Eur. Microbiol. Soc.) Microbiol. Lett. 273:157-165.

Johnson, B., and Blevins, R. 1994. NMR View: A computer program for the visualization and analysis of NMR data. J. Biomol. NMR 4:603-614.

Jones, J., and Dangl, J. 2006. The plant immune system. Nature 444:323329

Keegan, R., and Winn, M. 2008. MrBUMP: An automated pipeline for molecular replacement. Acta Crystallogr. D 64:119-124.

Kerff, F., Amoroso, A., Herman, R., Sauvage, E., Petrella, S., Filée, P., Charlier, P., Joris, B., Tabuchi, A., Nikolaidis, N., and Cosgrove, D. J. 2008. Crystal structure and activity of Bacillus subtilis YoaJ (EXLX1), a bacterial expansin that promotes root colonization. Proc. Natl. Acad. Sci. U.S.A. 105:16876-16881.

Langmead, B., Trapnell, C., Pop, M., and Salzberg, S. L. 2009. Ultrafast and memory efficient alignment of short DNA sequences to the human genome. Genome Biol. 10:R25.

Leal, G. A, Gomes, L. H., Albuquerque, P. S. B., Tavares, F. C. and Figueira, A. 2010. Searching for Moniliophthora perniciosa pathogenicity genes. Fungal Biol. 114:842-854.

Lehotzky, R., Partch, C., Mukherjee, S., Cash, H., Goldman, W., Gardner, K., and Hooper, L. 2010. Molecular basis for peptidoglycan recognition by a bactericidal lectin. Proc. Natl. Acad. Sci. U.S.A. 107:7722-7727.

Leslie, A. 1992. Recent changes to the MOSFLM package for processing film and image plate data. Joint CCP4 +ESF-EAMCB Newsl. Protein Crystallogr. 26:27-33

Lomakin, A., Chung, D., Benedek, G., Kirschner, D., and Teplow, D. 1996. On the nucleation and growth of amyloid beta -protein fibrils: Detection of nuclei and quantitation of rate constants. Proc. Natl. Acad. Sci. U.S.A. 93:1125-1129.
Lombardi, L., Faoro, F., Luti, S., Baccelli, I., Martellini, F., Bernardi, R. Picciarelli, P., Scala, A., and Pazzagli, L. 2013. Differential timing of defense-related responses induced by cerato-platanin and cerato-populin, two non-catalytic fungal elicitors. Physiol. Plant. doi: 10.1111/ppl.12041. Published online.

Marelli, J., Maximova, S., Gramacho, K., Kang, S., and Guiltinan, M. 2009. Infection biology of Moniliophthora perniciosa on Theobroma cacao and alternate solanaceous hosts. Trop. Plant Biol. 2:149-160.

Martellini, F., Faoro, F., Carresi, L., Pantera, B., Baccelli, I., Maffi, D., Tiribilli, B., Sbrana, F., Luti, S., Comparini, C., Bernardi, R., Cappugi, G., Scala, A., and Luigia Pazzagli, L. 2012. Cerato-populin and ceratoplatanin, two non-catalytic proteins from phytopathogenic fungi, interact with hydrophobic inanimate surfaces and leaves. Mol. Biotechnol. doi:10.1007/s12033-012-9618-4. Published online.

McCoy, A., Grosse-Kunstleve, R., Adams, P., Winn, M., Storoni, L., and Read, R. 2007. Phaser crystallographic software. J. Appl. Crystallogr. 40:658-674.

Meinhardt, L., Rincones, J., Bailey, B., Aime, M., Griffith, G., Zhang, D. and Pereira, G. 2008. Moniliophthora perniciosa, the causal agent of Witches' broom disease of cacao: What's new from this old foe? Mol Plant. Pathol. 9:577-588.

Mishra, R., Sörgjerd, K., Nyström, S., Nordigården, A., Yu, Y., and Hammarström, P. 2007. Lysozyme amyloidogenesis is accelerated by specific nicking and fragmentation but decelerated by intact protein binding and conversion. J. Mol. Biol. 366:1029-1044.

Mondego, J. M. C., Carazzolle, M. F., Costa, G. G. L., Formighieri, E. F. Parizzi, L. P., Rincones, J., Cotomacci, C., Carraro, D. M., Cunha, A. F., Carrer, H., Vidal, R. O., Estrela, R. C., Garcia, O., Thomazella, D. P., de Oliveira, B. V., Pires, A. B., Rio, M. C., Araujo, M.,R., de Moraes, M. H., Castro, L. A., Gramacho, K. P., Goncalves, M. S., Moura Neto, J. P., Goes Neto, A., Barbosa, L. V., Guiltinan, M. J., Bailey, B.,A., Meinhardt, L. W., Cascardo, J. C., and Pereira, G. A. 2008. A genome survey of Moniliophthora perniciosa gives new insights into witches' broom disease of cacao. BMC Genomics 9:548.

Moores, B., Drolle, E., Attwood, S., Simons, J., and Leonenko, Z. 2011. Effect of surfaces on amyloid fibril formation. PloS One 6:e25954.

Mortazavi, A., Williams, B. A., McCue, K., Schaeffer, L., and Wold, B. 2008. Mapping and quantifying mammalian transcriptomes by RNASeq. Nat. Methods 5:621-628.

Murphy, R. 2007. Kinetics of amyloid formation and membrane interaction with amyloidogenic proteins. Biochim. Biophys. Acta 1768:19231934.

Ortega, A., Amorós D., and García de la Torre, J. 2011. Prediction of hydrodynamic and other solution properties of rigid proteins from atomic and residue-level models. Biophys. J. 101:892-898.

Pan, S., and Cole, G. 1995. Molecular and biochemical characterization of a Coccidioides immitis-specific antigen. Infect. Immun. 63:3994-4002.

Pazzagli, L., Cappugi, G., Manao, G., Camici, G., Santini, A., and Scala, A. 1999. Purification, characterization, and amino acid sequence of cerato-platanin, a new phytotoxic protein from Ceratocystis fimbriata $\mathrm{f}$. sp. platani. J. Biol. Chem. 274:24959-24964.

Pazzagli, L., Zoppi, C., Carresi, L., Tiribilli, B., Sbrana, F., Schiff, S., Pertinhez, T. A., Scala, A., and Cappugi, G. 2009. Characterization of ordered aggregates of cerato-platanin and their involvement in fungushost interactions. Biochem. Biophys. Acta 1790:1334-1344.

Petersen, T. N., Brunak, S., Von Heijne, G., and Nielsen, H. 2011. SignalP 4.0: Discriminating signal peptides from transmembrane regions. Nat. Methods 8:785-786.

Pires, A. B. L., Gramacho, K. P., Silva, D. C., Góes-Neto, A., Silva, M. M., Muniz-Sobrinho, J. S., Porto, R. F., Villela-Dias, C., Brendel, M., Cascardo, J. C. M., and Pereira, G. A. G. 2009. Early development of Moniliophthora perniciosa basidiomata and developmentally regulated genes. BMC Microbiol. 9:158.

Rincones, J., Scarpari, L. M., Carazzolle, M. F., Mondego, J. M. C., Formighieri, E. F., Barau, J. G., Costa, G. G. L., Carraro, D. M. Brentani, H. P., Vilas-boas, L. A., de Oliveira, B. V., Sabha, M., Dias, R., Cascardo, J. M., Azevedo, R. A., Meinhardt,L. W., and Pereira, G. A. G. 2008. Differential gene expression between the biotrophic-like and saprotrophic mycelia of the witches' broom pathogen Moniliophthora perniciosa. Mol. Plant-Microbe Interact. 21:891-908.

Scarpari, L., Meinhardt, L., Mazzafera, P., Pomella, A., Schiavinato, M., Cascardo, J., and Pereira, G. 2005. Biochemical changes during the development of witches' broom: The most important disease of cocoa in Brazil caused by Crinipellis perniciosa. J. Exp. Bot. 56:865-877.

Seidl, V., Marchetti, M., Schandl, R., Allmaier, G., and Kubicek, C. 2006. Epl1, the major secreted protein of Hypocrea atroviridis on glucose, is a member of a strongly conserved protein family comprising plant defense response elicitors. FEBS (Fed. Eur. Biochem. Soc.) J. 273:43464359.

Sheldrick, G. 2010. Experimental phasing with SHELXC/D/E: Combining 
chain tracing with density modification. Acta Crystallogr. D 66:479-485.

Slupsky, C., Boyko, R., Booth, V., and Sykes, B. 2003. Smartnotebook: A semi-automated approach to protein sequential NMR resonance assignments. J. Biomol. NMR 27:313-321.

Stanke, M., Steinkamp, R., Waack, S., and Morgenstern, B. 2004. AUGUSTUS: A web server for gene finding in eukaryotes. Nucleic Acids Res. 32:W309-W312.

Tsiroulnikov, K., Chobert, J., and Haertlé, T. 2006. Copper-dependent degradation of recombinant ovine prion protein. Phosphatidylinositol stimulates aggregation and copper-driven disappearance of prion protein. FEBS (Fed. Eur. Biochem. Soc.) J. 273:1959-1965.

Uversky, V., and Fink, A. 2004. Conformational constraints for amyloid fibrillation: The importance of being unfolded. Biochem. Biophys. Acta 1698:131-153.

Vagin, A., Steiner, R., Lebedev, A., Potterton, L., McNicholas, S., Long, F., and Murshudov, G. 2004. REFMAC5 dictionary: Organization of prior chemical knowledge and guidelines for its use. Acta Crystallogr. D 60:2184-2195.

van Loon, L. C., Rep, M., and Pieterse, C. M. J. 2006. Significance of inducible defense-related proteins in infected plants. Annu. Rev. Phytopathol. 44:135-162.

Vargas, W., Djonović, S., Sukno, S., and Kenerley, C. 2008. Dimerization controls the activity of fungal elicitors that trigger systemic resistance in plants. J. Biol. Chem. 283:19804-19815.
Whiteford, J., and Spanu, P. 2002. Hydrophobins and the interactions between fungi and plants. Mol. Plant Pathol. 3:391-400.

Wilson, L., Idnurm, A., and Howlett, B. 2002. Characterization of a gene (sp1) encoding a secreted protein from Leptosphaeria maculans, the blackleg pathogen of Brassica napus. Mol. Plant Pathol. 3:487-493.

Wittekind, M., and Mueller, L. 1993. HNCACB, a high-sensitivity 3D NMR experiment to correlate amide-proton and nitrogen resonances with the alpha- and beta-carbon resonances in proteins. J. Magn. Reson. Ser. B 101:201-205.

Wösten, H., and de Vocht, M. 2000. Hydrophobins, the fungal coat unravelled. Biochim. Biophys. Acta 1469:79-86.

Yamazaki, T., Lee, W., Arrowsmith, C., Muhandiram, D. R., and Kay, L.E. 1994. A suite of triple resonance NMR experiments for the backbone assignment of ${ }^{15} \mathrm{~N},{ }^{13} \mathrm{C},{ }^{2} \mathrm{H}$ labeled proteins with high sensitivity. J. Am. Chem. Soc. 116:11655-11666.

Yennawar, N., Li, L., Dudzinski, D., Tabuchi, A., and Cosgrove, D. 2006. Crystal structure and activities of EXPB1 (Zea m 1), a beta-expansin and group-1 pollen allergen from maize. Proc. Natl. Acad. Sci. U.S.A. 103:14664-14671.

Zaparoli, G., Cabrera, O., Medrano, F., Tiburcio, R., Lacerda, G., and Pereira, G. 2009. Identification of a second family of genes in Moniliophthora perniciosa, the causal agent of witches' broom disease in cacao, encoding necrosis-inducing proteins similar to cerato-platanins. Mycol. Res. 113:61-72. 